\title{
Chemogenetic Silencing of Neurons in Retrosplenial Cortex Disrupts Sensory Preconditioning
}

\author{
Siobhan Robinson, ${ }^{1}$ Travis P. Todd, ${ }^{1}$ Anna R. Pasternak, ${ }^{1}$ Bryan W. Luikart, ${ }^{2}$ Patrick D. Skelton, ${ }^{2}$ Daniel J. Urban, ${ }^{3}$ \\ and David J. Bucci ${ }^{1}$ \\ ${ }^{1}$ Department of Psychological and Brain Sciences, Dartmouth College, Hanover, New Hampshire 03755, 22Department of Physiology and Neurobiology, \\ Geisel School of Medicine at Dartmouth, Lebanon, New Hampshire 03756, and ${ }^{3}$ Department of Pharmacology, University of North Carolina School of \\ Medicine, Chapel Hill, North Carolina 27599
}

An essential aspect of episodic memory is the formation of associations between neutral sensory cues in the environment. In light of recent evidence that this critical aspect of learning does not require the hippocampus, we tested the involvement of the retrosplenial cortex (RSC) in this process using a chemogenetic approach that allowed us to temporarily silence neurons along the entire rostrocaudal extent of the RSC. A viral vector containing the gene for a synthetic inhibitory G-protein-coupled receptor (hM4Di) was infused into RSC. When the receptor was later activated by systemic injection of clozapine- $N$-oxide, neural activity in RSC was transiently silenced (confirmed using a patch-clamp procedure). Rats expressing hM4Di and control rats were trained in a sensory preconditioning procedure in which a tone and light were paired on some trials and a white noise stimulus was presented alone on the other trials during the Preconditioning phase. Thus, rats were given the opportunity to form an association between a tone and a light in the absence of reinforcement. Later, the light was paired with food. During the test phase when the auditory cues were presented alone, controls exhibited more conditioned responding during presentation of the tone compared with the white noise reflecting the prior formation of a tone-light association. Silencing RSC neurons during the Preconditioning phase prevented the formation of an association between the tone and light and eliminated the sensory preconditioning effect. These findings indicate that RSC may contribute to episodic memory formation by linking essential sensory stimuli during learning.

Key words: DREADD; episodic; hippocampus; learning; parahippocampal; retrosplenial

\section{Introduction}

Episodic memory involves binding individual objects or events together in place and time (Cohen and Eichenbaum, 1993; Davachi, 2006). Fundamental to this process is the formation of associations between sensory stimuli even in the absence of reinforcement, for example, the linking together of stimuli that compose the environment in which the object/ event occurs. Although the hippocampus has a central role in episodic memory (Tulving and Markowitsch, 1998), recent studies indicate that the hippocampus itself is not active or necessary when these initial stimulus-stimulus associations

Received April 3, 2014; revised June 13, 2014; accepted July 8, 2014.

Author contributions: S.R. and D.J.B. designed research; S.R., T.P.T., A.R.P., B.W.L., and P.D.S. performed research;D.J.U. contributed unpublished reagents/analytic tools; D.J.B. analyzed data; S.R., T.P.T., and D.J.B. wrote the paper.

Research is supported by National Science Foundation Grant 0922075 (D.J.B.) and National Institutes Health Grant MH092991 (S.R.). We thank Dr. Kyle Smith for technical assistance and valuable comments on prior versions of this manuscript and Dr. Bryan Roth for assistance with the chemogenetic methodology. We also thank Drs. George Wolford and Jay Hull for assistance with the statistical analyses.

The authors declare no competing financial interests.

Correspondence should be addressed to David J. Bucci, PhD, Dartmouth College, Department of Psychological and Brain Sciences, 6207 Moore Hall, Hanover, NH 03755. E-mail: david.j.bucci@dartmouth.edu.

S. Robinson's present address: Department of Neuroscience, Oberlin College, Oberlin, $\mathrm{OH} 44074$.

D. J. Urban's present address: Department of Cell Biology, Duke University, Durham, NC 27710.

DOI:10.1523/JNEUROSCI.1349-14.2014

Copyright $\odot 2014$ the authors $\quad 0270-6474 / 14 / 3410982-07 \$ 15.00 / 0$ are formed (Iordanova et al., 2011; Wimmer and Shohamy, 2012), suggesting that another, unknown, region(s) is responsible for this function.

The retrosplenial cortex (RSC) may be particularly well suited for this purpose. RSC receives input from multiple cortical and thalamic sensory regions and is strongly interconnected with the postrhinal and medial entorhinal cortices and the postsubiculum (Fig. 1; Kobayashi and Amaral, 2003, 2007; Sugar et al., 2011). Thus, RSC is positioned at the interface between sensory regions and the medial temporal lobe memory system.

Indeed, previous reports (Kobayashi and Amaral, 2007; Vann et al., 2009; Sugar et al., 2011; Robinson et al., 2011) indicate that RSC may serve as a sensory integration center. However, a thorough test of this hypothesis requires the ability to temporarily inactivate RSC during specific phases of learning. This has been challenging to date because the large size and intrinsic organization of RSC (Shibata et al., 2009) prohibits conventional inactivation methods more suited for smaller brain regions.

This limitation is surmountable with the advent of chemogenetics (designer-receptors-exclusively activated-by-designerdrugs, DREADDs; Armbruster et al., 2007; Urban and Roth, 2014). This approach involves infusing a viral vector that contains the gene for a synthetic inhibitory G-protein-coupled receptor (hM4Di) into multiple brain locations (e.g., along the rostrocaudal extent of RSC). The receptor is subsequently ex- 


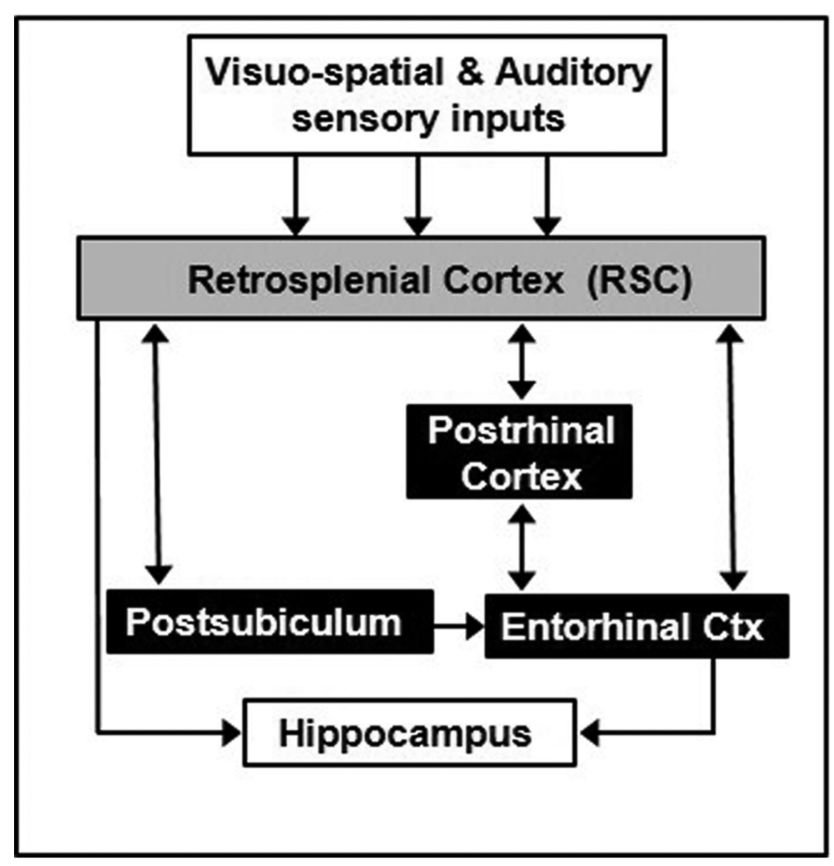

Figure 1. Schematic diagram of corticohippocampal circuitry involved in processing contextual information. Only the densest connections (black lines) are illustrated for simplicity.

pressed by neurons and can be activated for $\sim 2 \mathrm{~h}$ by systemic injection of clozapine- $\mathrm{N}$-oxide (CNO), an otherwise inert exogenous ligand.

The present study used chemogenetics to test the role of RSC in stimulus-stimulus learning during a sensory preconditioning task (Fig. 2A). During Preconditioning, a tone was paired with a light on half of the trials; on other trials a white-noise stimulus was presented alone. No food was delivered during this phase, thus rats could form an association between the tone and light in the absence of reinforcement. During Conditioning the same light was paired with food. When the tone and white noise were each presented alone during the subsequent Test session, control rats exhibited more conditioned responding to the tone, as shown previously (Holland and Ross, 1983; Blaisdell et al., 2009). This occurs even though the tone was never paired directly with the food, thus reflecting the formation of a stimulus-stimulus association between the tone and light during the Preconditioning phase. Notably, permanent lesions of RSC disrupt performance on this multiphase sensory preconditioning paradigm (Robinson et al., 2011), but fail to distinguish whether the RSC is involved in acquisition or expression of learning. Thus, to test whether RSC was necessary for forming the initial stimulus-stimulus association between the tone and the light, neurons spanning RSC were temporarily silenced before each Preconditioning session, but then were left undisturbed during subsequent phases of the task.

\section{Materials and Methods}

Viral constructs. A synapsin-promoter driven adeno-associated viral vector, AAV-hSyn-HA-hM4Di-IRES-mCitrine (serotype 8, viral titer = $4.2 \times 10^{12}$ particles/ml, UNC Gene Therapy Center) was used to transduce RSC neurons with hM4Di. An IRES mCitrine reporter allowed for visualization of expression. In five rats, a different hM4Di-containing construct was used (Lenti-GFP-t2a-hM4Di) because it contained a reporter (GFP) that was compatible with the microscope that was used to identify hM4Di-expressing neurons in the patch-clamp experiment. A third construct, AAV-hSyn-GFP (serotype 8), lacked the hM4Di gene and was used to control for nonspecific virus effects.

Subjects and surgery. Fifty-three male Long-Evans rats ( $\sim 250 \mathrm{~g}$; Harlan Laboratories) were maintained at $85 \%$ of free-feeding weight during the study. Rats were anesthetized and prepared for craniotomy as described previously (Robinson et al., 2011). Rats received 10 infusions (Table 1) of AAV-hSyn-HA-hM4Di-IRES-mCitrine $(n=31)$, LentiGFP-t2a-hM4Di $(n=5)$, AAV-hSyn-GFP $(n=4)$, or vehicle $(1 \times$ PBS, $n=13$ ). All infusions were performed using a 28 gauge Hamilton syringe connected to an infusion pump (Stoelting). At each site, $0.8 \mu \mathrm{l}$ of the AAV constructs or $1.5 \mu \mathrm{l}$ of the Lenti construct (to achieve comparable spread of the virus) was infused at a rate of $0.15 \mu \mathrm{l} / \mathrm{min}$. The needle was left in place for $30 \mathrm{~s}$ before and $2 \mathrm{~min}$ following each infusion. Rats recovered for 3 weeks before the start of training.

Behavioral apparatus. Standard operant conditioning chambers (Med Associates) were enclosed in sound-attenuating chambers (SAC) outfitted with an exhaust fan $(\sim 68 \mathrm{~dB})$. A red $2.8 \mathrm{~W}$ bulb was mounted on the ceiling of the SAC to provide dim background illumination. A food cup was recessed in the center of the front wall and a $2.8 \mathrm{~W}$ house light was mounted on the opposite wall and served as the visual stimulus (flashed at $2 \mathrm{~Hz}$ ). The background lamp was turned off while the stimulus light flashed. A speaker was used to present the auditory stimuli (a $1500 \mathrm{~Hz}, 78$ $\mathrm{dB}$ pure tone and a $78 \mathrm{~dB}$ white noise). Infrared photocells mounted just inside the food cup detected head entries.

Behavioral procedures. During the Preconditioning phase (Fig. 2A), rats received four daily 64 -min training sessions. On six of the trials, the tone ("preconditioned cue") was presented for $10 \mathrm{~s}$, followed immediately by a 5 -s presentation of the flashing light stimulus. During the other six trials the white noise ("unpaired cue") was presented alone for $10 \mathrm{~s}$ (intermixed trials, average intertrial interval (ITI) $=4.5 \mathrm{~min}$ ). During the Conditioning phase, seven daily 64 -min sessions each consisted of eight presentations of the flashing light (7 min ITI) followed immediately by delivery of two $45 \mathrm{mg}$ food pellets (BioServe). During the single Test session each of the two auditory stimuli were presented alone six times on separate intermixed trials (78-min session). As shown in our previous studies, equivalent levels of sensory preconditioning occur regardless of which auditory cue is used as the sensory preconditioned cue or the unpaired cue (Robinson et al., 2011; Robinson and Bucci, 2012).

Drug preparation and administration. CNO (Enzo Life Sciences) was prepared daily in sterile water (vehicle) and injected intraperitoneally (1 $\mathrm{mg} / \mathrm{kg}, 1.0 \mathrm{ml} / \mathrm{kg}$, or vehicle) $30 \mathrm{~min}$ before each Preconditioning session. This dose was based on pilot studies indicating that $1 \mathrm{mg} / \mathrm{kg}$ had no effect on contextual fear learning, while higher doses resulted in an exaggerated fear response (D.J.B.'s unpublished data). No injections were made before the Conditioning sessions or Test session.

Treatment groups. In addition to the experimental group (hM4Di$\mathrm{CNO}$ ), four control groups were included in the experiment (Table 2): Group VEH-VEH received infusions of PBS during surgery and was administered sterile water before Preconditioning. Group VEH-CNO received PBS during surgery and was administered CNO. Group hM4DiVEH received hM4Di during surgery and was administered sterile water. Group GFP-CNO received infusions of the GFP control virus and was administered CNO. These four control groups were specifically chosen to evaluate several discrete factors, in addition to the experimental manipulation, which could affect sensory preconditioning. In particular, our purpose was to (1) test that any effect observed in Group hM4DiCNO was due to activation of the hM4Di receptor specifically by $\mathrm{CNO}$ (by including Group hM4Di-VEH); (2) test that the effect was produced by $\mathrm{CNO}$ acting specifically on hM4Di (by including Group GFP-CNO); (3) test whether the effect was due to the combination of a foreign substance (a viral vector) and CNO (also addressed with Group GFP-CNO); and (4) test whether the effect was merely due to injection of CNO (by including Group VEH-CNO, and thus Group VEH-VEH as an appropriate comparison). Importantly, these factors have not yet been evaluated in published studies that have used the DREADD methodology.

Behavioral observations and data analysis. Beam break data during Conditioning were collected during the $5 \mathrm{~s}$ presentation of the visual stimulus (Light epoch) and during the $5 \mathrm{~s}$ period immediately after food was delivered (Food epoch; Fig. 2A). Data were subjected to repeated- 

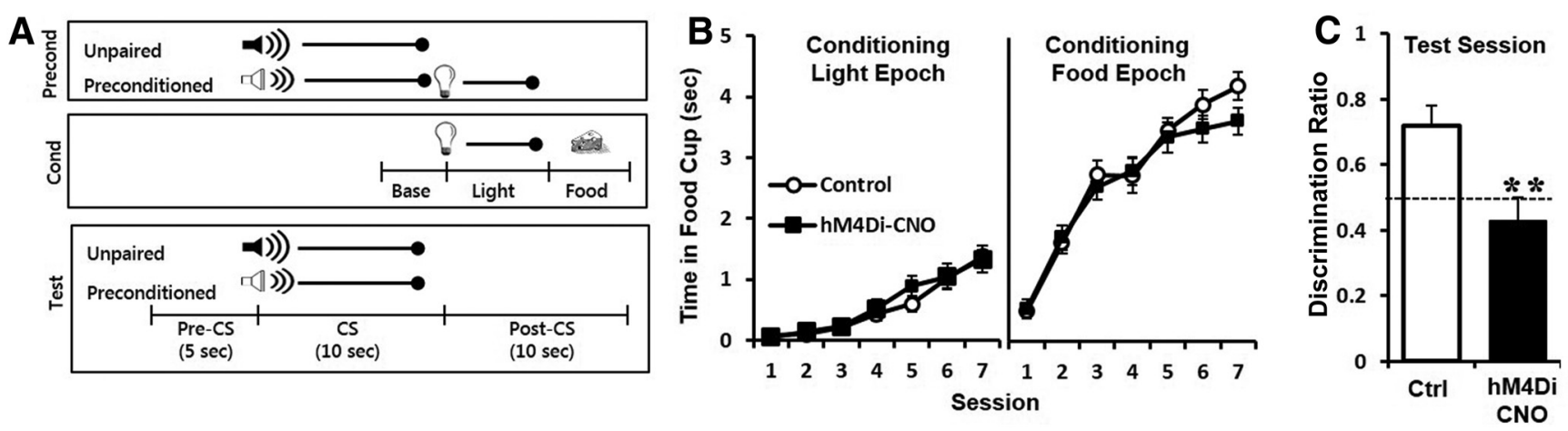

Figure 2. A, Schematic diagram of the sensory preconditioning task adapted from Brogden, 1939. The time line and epochs noted on the bottom refer to the time periods used in the analyses described in Materials and Methods. $\boldsymbol{B}$, Food-cup responding during presentation of the Light and during the Food epoch in the Conditioning phase. $\boldsymbol{C}$, Discrimination ratios during the Test session. Dotted line indicates equal amounts of conditioned responding to both auditory cues (i.e., no sensory preconditioning). Data are means \pm SEM, ${ }^{* *} p<0.005$.

Table 1. Stereotactic coordinates for infusions into RSC

\begin{tabular}{lll}
\hline AP & ML & DV \\
\hline-2.0 & \pm 0.3 & -2.6 \\
-3.5 & \pm 0.3 & -2.4 \\
-5.0 & \pm 0.3 & -2.6 \\
-6.5 & \pm 1.0 & -2.4 \\
-8.0 & \pm 1.5 & -2.5
\end{tabular}

All AP, ML, and DV measurements are derived from bregma, midline, and skull surface, respectively (measurements are in millimeters), and based on Paxinos and Watson (1998).

Table 2. Group designations and sample sizes

\begin{tabular}{llll}
\hline Group & $\begin{array}{l}\text { Surgical } \\
\text { treatment }\end{array}$ & $\begin{array}{l}\text { Drug treatment during } \\
\text { training }\end{array}$ & Final sample sizes (n) \\
\hline $\begin{array}{c}\text { Experimental } \\
\text { hM4Di-CNO }\end{array}$ & hM4di & CNO & 19 (17 AAV-hM4Di, 2 Lenti-hM4Di) \\
$\begin{array}{c}\text { Controls } \\
\text { hM4Di-VEH }\end{array}$ & hM4di & Water & 6 (4 AAV-hM4Di, 2 Lenti-hM4Di) \\
GFP-CNO & GFP & CNO & 4 \\
VEH-CNO & PBS & CNO & 4 \\
VEH-VEH & PBS & Water & 7 \\
\hline
\end{tabular}

Table 3. Food cup behavior exhibited by rats in the four control groups

\begin{tabular}{lll}
\hline Group & $\begin{array}{l}\text { Mean responding during } \\
\text { conditioning }(\mathrm{sec})\end{array}$ & $\begin{array}{l}\text { Discrimination ratio during } \\
\text { test session }\end{array}$ \\
\hline hM4Di-VEH & $0.4 \pm 0.1$ & $0.69 \pm 0.09$ \\
GFP-CNO & $0.6 \pm 0.1$ & $0.74 \pm 0.19$ \\
VEH-CNO & $0.6 \pm 0.3$ & $0.66 \pm 0.19$ \\
VEH-VEH & $0.5 \pm 0.1$ & $0.76 \pm 0.11$ \\
\hline
\end{tabular}

measures ANOVA (rmANOVA). There were no significant differences in food-cup behavior between the four control groups (see Results); thus, the data from these groups were pooled and compared with the data obtained from the experimental (hM4Di-CNO) group using rmANOVA.

During the critical Test session, beam break data were collected during the $10 \mathrm{~s}$ presentations of the auditory stimuli and during the $10 \mathrm{~s}$ period following presentation of the auditory stimuli (post-CS epoch). The primary measure of interest was the amount of time spent in the food cup during the post-CS epoch, because this period corresponded to the time that the visual stimulus was presented after the tone during Preconditioning and to the time that food was presented during Conditioning. Thus, if rats formed an association between the tone and light in the Preconditioning phase, food-cup behavior was expected to be particularly high during the post-CS epoch. The strength of sensory preconditioning in the control and experimental groups was assessed using a discrimination ratio (to take into account individual differences in food- cup behavior; Iordanova et al., 2011; Robinson et al., 2011), defined as the amount of responding observed during the post-CS period following presentation of the tone divided by the sum of the post-CS responding observed following the tone and the white noise.

We previously demonstrated that permanent lesions of RSC performed before training abolished the sensory preconditioning effect (Robinson et al., 2011). This finding led us to test the specific a priori hypothesis that temporarily silencing RSC neurons during the Preconditioning phase (i.e., specifically and only during the stimulusstimulus learning phase) would reduce the discrimination ratio during the Test phase. This was tested using a one-way ANOVA $(1 \times$ 5 ), which included a planned contrast (Hays, 1994) that pitted the discrimination ratio of the experimental group against the average of the four control groups. Three additional contrasts compared the discrimination ratios among the different control groups. As a follow-up analysis, one-sample $t$ tests were used to compare the discrimination ratios to an expected value of 0.5 (i.e., equal amounts of conditioning to the two cues, thus no sensory preconditioning). Alpha levels of 0.05 were used for all analyses.

Virus expression and analysis. Rats were anesthetized and transcardially perfused with saline followed by $4 \%$ paraformaldehyde. Coronal brain sections $(40 \mu \mathrm{m})$ were collected at $320 \mu \mathrm{m}$ intervals throughout the rostrocaudal extent of the RSC. Neurons that expressed the hM4Di receptor were visualized with immunocytochemistry for GFP (1:1000 dilution of anti-GFP; Novus Biologicals). The secondary antibody [Alexa Fluor 488 goat anti-rabbit IgG $(\mathrm{H}+\mathrm{L})$; Invitrogen Life Technologies] was used at a dilution of 1:250. Sections were mounted and coverslipped using Vectashield (Vector Laboratories). An observer who was blind to experimental condition outlined the location of fluorescent neurons using Stereo Investigator software (version 9; MicroBrightField) using an Axioskop I microscope (Zeiss).

Patch-clamp procedure. A patch-clamp slice preparation was used to measure the responsiveness of hM4Di-infected neurons to CNO. Two rats that received infusions of Lenti-GFP-t2a-hM4Di were over anesthetized with Avertin and perfused with an ice-cold solution containing the following (in mM): 110 choline-Cl, $10 \mathrm{D}$-glucose, $7 \mathrm{MgCl}_{2}, 2.5 \mathrm{KCl}, 1.25$ $\mathrm{NaH}_{2} \mathrm{PO}_{4} \cdot 2 \mathrm{H}_{2} \mathrm{O}, 0.5 \mathrm{CaCl}_{2}, 1.3 \mathrm{Na}$-ascorbate, and $25 \mathrm{NaHCO}_{3}$, bubbled with $95 \% \mathrm{O}_{2}-5 \% \mathrm{CO}_{2}$. Whole-cell patch-clamp recordings from slices $(290 \mu \mathrm{m})$ containing RSC were performed in artificial CSF (aCSF) and using a K-gluconate internal solution. A series of $500 \mathrm{~ms}$ current pulses varying in intensity between 40 to $520 \mathrm{pA}$ in $40 \mathrm{pA}$ increments were injected into GFP-positive neurons and the frequency of resulting action potentials in standard aCSF and in aCSF containing $10 \mu \mathrm{M}$ CNO was recorded. For each cell, firing frequency was expressed as percentage maximum firing frequency. Series resistance was monitored and data discarded if it increased by $>10 \mathrm{M} \Omega$. Recordings were sampled at $80 \mathrm{kHz}$ (Multiclamp 700B; Molecular Devices) and action potentials were detected and measured using a template (AxoGraph X) and reviewed manually. Spike threshold was determined by taking $10 \%$ of the first 

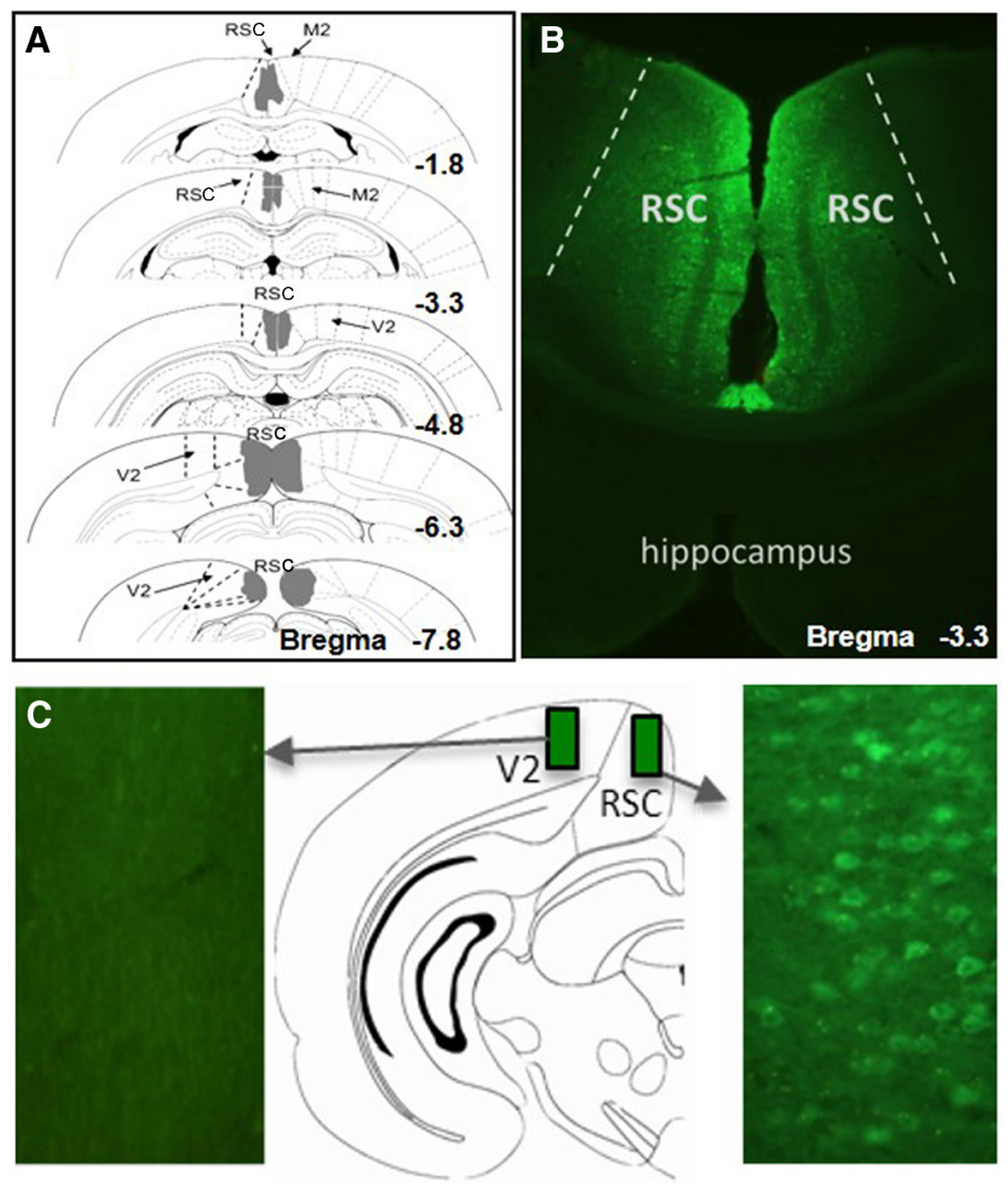

Figure 3. $A$, Schematic diagram of expression of hM4Di in a representative rat infused with AAV-hSyn-HA-hM4Di-IRESmCitrine in RSC. $\boldsymbol{B}$, Fluorescent labeling in RSC at $4 \times$ magnification and (C) $20 \times$ magnification.

derivative of the voltage trace. A two-way ANOVA was performed with stimulus intensity and treatment as factors and comparisons were made with Bonferroni post hoc (GraphPad Prism).

\section{Results}

\section{Behavior}

The behavioral data from seven rats showed little evidence of conditioning to the light ( $>2$ SDs from the overall mean). This precludes interpretation of responding during the Test session and the rats were excluded (final $n$ s indicated in Table 2). Foodcup behavior during the Conditioning phase did not differ among the four control groups ( $p s>0.6$ ), thus their data were pooled. As expected, there were no differences in behavior between rats in the hM4Di-CNO group that received the AAVhM4Di construct and those that received the Lenti-hM4Di construct $(p s>0.3)$.

Importantly, as shown in Figure $2 B$, control and experimental groups exhibited comparable levels of conditioning to the light. The amount of time spent with head in the food cup during presentation of the light increased over sessions $\left(F_{(6,228)}=61.6\right.$, $p<0.0001)$, but there was neither a main effect of Group $(p>$ $0.7)$ nor a significant Group $\times$ Session interaction $(p>0.6)$, indicating that conditioning to the light was comparable in the control group and the hM4Di-CNO group. Similarly, rats in both groups spent an increasing amount of time in the food cup when food was delivered $\left(F_{(6,228)}=58.2, p<0.0001\right)$ and there was neither a main effect of Group $(p>0.5)$ nor a significant Group $\times$ Session interaction $(p>0.4)$. Thus, any effects observed during the Test phase could not be attributed to a difference in learning the light-food association or to a difference in motivation to obtain food.

The critical Test session data are illustrated in Figure $2 C$. The planned contrast comparing the experimental group against the average of the four control groups was significant $\left(t_{(35)}=2.83, p=\right.$ $0.008)$. The point estimate for the contrast (i.e., the difference in the discrimination ratio for the experimental group vs the average of the four control groups) was -0.278 . Bootstrapped $95 \%$ confidence intervals around that effect ranged from -0.456 to -0.071 . Cohen's $d$ for the contrast was 0.908 , a robust effect suggesting that the experimental group spent significantly more time with their heads in the food cup in response to presentation of the sensory preconditioned cue compared with their food-cup responses to presentations of the unpaired cue. Bootstrapped 95\% confidence intervals around Cohen's $d$ ranged from 0.17 to 1.61. In addition, we found that the planned contrast that compared the discrimination ratio of the experimental group to the mean discrimination ratio of the control groups accounted for just over $90 \%$ of the sum of squares in the omnibus main effect. The remaining sum of squares was not accounted for by any of the other orthogonal contrasts. In other words, none of the comparisons among the control groups was statistically significant ( $p s>0.6)$.

A follow-up analysis further supported the main findings by indicating that the discrimination ratio for the control group was significantly higher than $0.5\left(t_{(20)}=3.6, p<0.002\right)$, indicating that control rats spent more time in the food cup following presentation of the tone (preconditioned cue) compared with the white noise (unpaired cue). In contrast, rats that expressed the hM4Di receptor in RSC and were treated with $\mathrm{CNO}$ before each Preconditioning session (group hM4Di-CNO) did not have a discrimination ratio that differed from $0.5(p>0.4)$.

In addition, we tested for a difference in the overall levels of food-cup responding during the Test phase to determine whether the experimental manipulation produced any nonspecific changes in baseline responding. An independent measures $t$ test did not reveal a significant difference between the controls and experimental group $\left(t_{(38)}=0.7, p>0.5\right)$. The mean levels of responding were $0.74 \pm 0.13 \mathrm{~s}$ for the control rats and $0.92 \pm$ $0.22 \mathrm{~s}$ for the rats in the hM4Di-CNO group.

\section{Histology}

An example of expression of the mCitrine reporter in RSC is shown in Figure 3. Five rats that received infusions of AAV-hSyn- 
HA-hM4Di-IRES-mCitrine and one rat that received infusions of Lenti-GFP-t2ahM4Di did not exhibit expression and their data were excluded from analysis. In the remaining rats, expression of the reporter was comparable and evident along most of the rostrocaudal extent of RSC as illustrated in Figure $3 \mathrm{~A}$. Fluorescent neurons were only observed in RSC, indicating that the virus infusion did not spread into nearby areas (Fig. $3 B, C$ ). In addition, the expression of the reporter in Group GFP-CNO was comparable to that observed in the hM4Di-CNO group.

\section{Electrophysiology}

A two-way ANOVA revealed a significant decrease in firing frequency after $\mathrm{CNO}$ wash-on $\left(F_{(1,12)}=33.4, p<0.0001, n=\right.$ $5)$. There were significant decreases in firing frequency in response to current steps of 200,240 , and $280 \mathrm{pA}$ ( $t \mathrm{~s}>3.2, \mathrm{ps}<$ $0.05)$ as illustrated in Figure 4. Firing frequency in response to current injections of 200,240, and 280 pA decreased from $22.0 \pm$ 7.7 (mean \pm SEM), $28.8 \pm 7.9$, and $34.8 \pm 8.5 \mathrm{~Hz}$ to $1.2 \pm 0.8$, $12.0 \pm 4.9$, and $19.6 \pm 6.6 \mathrm{~Hz}$, respectively. The minimum current injection required to elicit at least one action potential increased from $144 \pm 27.1$ to $232 \pm 15.0 \mathrm{pA}$. An increase in spike threshold $\left(-43.3 \pm 1.1\right.$ to $\left.-37.8 \pm 2.7 \mathrm{mV} ; t_{(4)}=3.2, p<0.05\right)$ and spike rise time $\left(0.13 \pm 0.01\right.$ to $0.16 \pm 0.02 \mathrm{~ms} ; t_{(4)}=3.0, p<$ 0.05) was also observed when $\mathrm{CNO}$ was in the bath. Resting membrane potential $(p>0.7)$, spike half-width $(p>0.05)$, and spike latency $(p>0.5)$ remained unchanged.

\section{Discussion}

A fundamental component of episodic memory is the formation of associations between the sensory stimuli that form the environment in which an object or event occurs, often in the absence of any reinforcement. The present study tested the role of the RSC in this process using a sensory preconditioning task. Control rats formed an association between the light and tone during the Preconditioning phase, as evidenced by greater levels of conditioned food-cup behavior during presentation of the tone compared with the white noise during the Test phase. In contrast, when RSC neurons were silenced during Preconditioning, rats exhibited comparable amounts of food-cup behavior to the two auditory stimuli during the Test phase. These data indicate that the RSC needs to be active when the tone-light association is formed and support an essential role for RSC for learning about neutral sensory cues in the environment.

The importance of this finding is underscored by the results of two recent studies showing that the hippocampus itself is not active (Wimmer and Shohamy, 2012) or necessary (Iordanova et al., 2011) for forming initial stimulus-stimulus associations. In the study by Iordanova et al. (2011), rats were tested in a procedure that is very similar to the one used here. During the first phase of training, a tone was presented in one context and a second auditory stimulus (click) was paired with a different context. In the second phase of conditioning, the tone was paired with footshock in a new context. Finally, rats received a test session in which they were re-exposed to the two training contexts without the auditory cues or shock being delivered. Control rats exhibited more freezing in the context that had been paired with the tone compared with the context that had been paired with the clicks. This result suggests that during the first phase, rats formed an association between each context and the auditory cue that was presented there, i.e., a sensory preconditioning effect. Importantly, temporarily blocking NMDA glutamate receptors in the hippocampus during the second phase of conditioning, but not the first phase, impaired this effect. Thus, the hippocampus is not necessary for the formation of initial associations, although it is appears to be necessary for retrieving those associations. Similarly, Wimmer and Shohamy (2012), using a sensory preconditioning paradigm in humans, demonstrated that the hippocampus is not active when stimulus-stimulus associations are being formed, but is active when these associations are being retrieved. The present findings complement and extend these studies of hippocampal function by showing that the RSC may have a pivotal role in forming associations between sensory cues in the environment.

The current findings are also consistent with the results of a series of studies in rats with permanent lesions of RSC. For example, RSC lesions have been shown to impair spatial learning (Harker and Whishaw, 2002; Vann and Aggleton, 2002; Keene and Bucci, 2009) as well as contextual fear conditioning (Keene and Bucci, 2008b). Hence, RSC is necessary when tasks require the formation of arbitrary associations among the background stimuli in the environment. Furthermore, the effects of RSC lesions are not limited to situations in which stimuli are static background cues; RSC damage also impaired the ability to form associations between phasic stimuli (a light and a tone presented for a discrete time period; Keene and Bucci, 2008a; Robinson et al., 2011). However, the interpretation of these previous findings is complicated by the presence of damage before any training, making it difficult to ascribe the behavioral effects to a particular stage of information processing. In fact, for this reason, most studies to date have only been able to conclude that RSC has a role in the recall of contextual or spatial information (Ranganath and Ritchey, 2012). However, by temporarily inactivating RSC neurons in the present study, we provide some of the first evidence that RSC neurons are also involved in the acquisition and encoding of stimulus-stimulus relationships.

The present data may further the interpretation of previous electrophysiological and neuroimaging studies that highlight a 
role for RSC in contextual information processing. For example, neural recording studies have shown that RSC is involved in distinguishing between different contexts (Smith et al., 2012). In addition, head direction and place cells have been observed in RSC while rats were performing spatial tasks (Chen et al., 1994; Cho and Sharp, 2001). Likewise, neuroimaging studies in humans demonstrate that RSC is active during tasks that require the processing of contextual associations (Bar and Aminoff, 2003; Kveraga et al., 2011) and during spatial navigation (Epstein, 2008). The present findings extend and complement this literature by demonstrating that the activity of RSC is necessary for forming associations between sensory stimuli in the environment.

A significant advantage of the chemogenetic approach used here is that it allows, for the first time, the temporary inactivation of neurons along the entire rostrocaudal extent of RSC. This was previously impossible because the length of RSC $(\sim 8 \mathrm{~mm}$ in the rat brain; Paxinos and Watson, 1998) precludes using traditional methods (i.e., muscimol or tetrodotoxin delivered through cannulae) to inactivate neurons throughout the entire RSC. For example, it would require that approximately five cannulae be implanted on each side of the brain to affect all of the RSC while still restricting the spread of the inactivating agent to the target region. This produces significant permanent tissue damage and is accompanied by the challenge of keeping all cannulae clean and patent over the course of training. Moreover, damage accumulates with repeated infusions of the inactivating agent. Although single-site inactivation of RSC has produced behavioral effects (Corcoran et al., 2011), this approach may run the risk of producing false negative data since only a very small portion of RSC is affected. In fact, in the study by Corcoran et al. (2012), blockade of NMDA receptors at a single site in RSC impaired the expression of contextual fear when the drug was administered during recall, but not when it was administered during acquisition. Although this was interpreted as suggesting that RSC was not involved in encoding contextual associations, the data presented here suggest instead that null effects may have been obtained in that study because an insufficient number of RSC neurons were affected. Indeed, the importance of manipulating neurons along the entire extent of RSC is demonstrated by recent anatomical data indicating that the intrinsic connectivity of the RSC is characterized by a significant amount of interconnectivity (Shibata et al., 2009).

As with any new technology, it is important to rule out inadvertent behavioral effects. We found that CNO itself did not affect sensory preconditioning, since rats infused with vehicle instead of a virus during surgery and treated with CNO during training exhibited normal sensory preconditioning. Similarly, the mere infusion of the viral vector containing hM4Di did not alter behavior since rats receiving the virus also exhibited normal sensory preconditioning when treated with vehicle during Preconditioning. Finally, the specificity of the effect induced by silencing RSC neurons was verified by showing that infusion of a virus that lacked hM4Di did not alter sensory preconditioning when those rats were treated with CNO. In addition, it is important to note that silencing RSC neurons in the experimental group during Preconditioning had no effect on learning the light-food association during Conditioning. Together, these data indicate that the impairments in sensory preconditioning were specifically due to the selective and temporary silencing of RSC neurons when the tone and light were paired during Preconditioning.
In the present study, the tone was used as the preconditioned cue and the white noise was used as the unpaired cue in all rats. Thus, it is possible that the behavioral effects observed in the control and experimental groups may have reflected general differences in associability or salience between the tone and white noise. However, several factors make this unlikely. For example, in our prior studies that used the same conditioning paradigm and stimuli, the sensory preconditioning effect was observed in normal rats regardless of which auditory cue was used as the preconditioned or unpaired cue (Robinson et al., 2011; Robinson and Bucci, 2012). Moreover, we found that permanent RSC damage disrupted sensory preconditioning regardless of whether the tone or white noise was used as the preconditioned or unpaired cue (Robinson et al., 2011). Furthermore, the cues we used were both auditory in nature, thus it would be highly unlikely that the RSC manipulation would have affected sensation/perception of one but not the other. In addition, prior studies have demonstrated that even when permanent RSC lesions are carried out, there are no general deficits in the ability to respond (or condition) to visual or auditory stimuli (Keene and Bucci, 2008a,b; Robinson et al., 2011). Finally, we have found that administering $\mathrm{hM} 4 \mathrm{Di}$ virus and/or CNO had no effects on learning associations between a light and food or a tone and shock (D.J.B.'s unpublished data).

In summary, the findings presented here indicate that the RSC has an essential role in forming associations between multiple sensory stimuli in the absence of reinforcement, a fundamental component of episodic memory. Future studies might use similar methods to determine whether RSC is also involved in retrieving these stimulus-stimulus associations.

\section{References}

Armbruster BN, Li X, Pausch MH, Herlitze S, Roth BL (2007) Evolving the lock to fit the key to create a family of $\mathrm{G}$ protein-coupled receptors potently activated by an inert ligand. Proc Natl Acad Sci U S A 104:51635168. CrossRef Medline

Bar M, Aminoff E (2003) Cortical analysis of visual context. Neuron 38: 347-358. CrossRef Medline

Blaisdell AP, Leising KJ, Stahlman WD, Waldmann MS (2009) Rats distinguish between absence of events and lack of information in sensory preconditioning. Int J Comp Psychol 22:1-18.

Brogden WJ (1939) Sensory preconditioning. J Exp Psychol 25:323-332. CrossRef

Chen LL, Lin LH, Green EJ, Barnes CA, McNaughton BL (1994) Headdirection cells in the rat posterior cortex. I. Anatomical distribution and behavioral modulation. Exp Brain Res 101:8-23. CrossRef Medline

Cho J, Sharp PE (2001) Head direction, place, and movement correlates for cells in the rat retrosplenial cortex. Behav Neurosci 115:3-25. CrossRef Medline

Cohen NJ, Eichenbaum H (1993) Memory, amnesia, and the hippocampal system. Cambridge, MA: MIT.

Corcoran KA, Donnan MD, Tronson NC, Guzmán YF, Gao C, Jovasevic V, Guedea AL, Radulovic J (2011) NMDA receptors in retrosplenial cortex are necessary for retrieval of recent and remote context fear memory. J Neurosci 31:11655-11659. CrossRef Medline

Davachi L (2006) Item, context and relational episodic encoding in humans. Curr Opin Neurobiol 16:693-700. CrossRef Medline

Epstein RA (2008) Parahippocampal and retrosplenial contributions to human spatial navigation. Trends Cogn Sci 12:388-396. CrossRef Medline

Harker KT, Whishaw IQ (2002) Impaired spatial performance in rats with retrosplenial lesions: importance of the spatial problem and the rat strain in identifying lesion effects in a swimming pool. J Neurosci 22:1155-1164. Medline

Hays W (1994) Statistics. New York: Wadsworth Publishing.

Holland PC, Ross RT (1983) Savings test for associations between neutral stimuli. Anim Learn Behav 11:83-90. CrossRef

Iordanova MD, Good M, Honey RC (2011) Retrieval-mediated learning in- 
volving episodes requires synaptic plasticity in the hippocampus. J Neurosci 31:7156-7162. CrossRef Medline

Keene CS, Bucci DJ (2008a) Involvement of the retrosplenial cortex in processing multiple conditioned stimuli. Behav Neurosci 122:651-658. CrossRef Medline

Keene CS, Bucci DJ (2008b) Neurotoxic lesions of retrosplenial cortex disrupt signaled and unsignaled contextual fear conditioning. Behav Neurosci 122:1070-1077. CrossRef Medline

Keene CS, Bucci DJ (2009) Damage to the retrosplenial cortex produces specific impairments in spatial working memory. Neurobiol Learn Mem 91:408-414. CrossRef Medline

Kobayashi Y, Amaral DG (2003) Macaque monkey retrosplenial cortex: II. Cortical afferents. J Comp Neurol 466:48-79. CrossRef Medline

Kobayashi Y, Amaral DG (2007) Macaque monkey retrosplenial cortex: III. Cortical efferents. J Comp Neurol 502:810-833. CrossRef Medline

Kveraga K, Ghuman AS, Kassam KS, Aminoff EA, Hämäläinen MS, Chaumon M, Bar M (2011) Early onset of neural synchronization in the contextual associations network. Proc Natl Acad Sci U S A 108:3389-3394. CrossRef Medline

Paxinos G, Watson C (1998) The rat brain in stereotaxic coordinates, Ed 4. San Diego, CA: Academic.

Ranganath C, Ritchey M (2012) Two cortical systems for memory-guided behaviour. Nat Rev Neurosci 13:713-726. CrossRef Medline

Robinson S, Keene CS, Iaccarino HF, Duan D, Bucci DJ (2011) Involvement of the retrosplenial cortex in forming associations between multiple sensory stimuli. Behav Neurosci 125:578-587. CrossRef Medline
Robinson S, Bucci DJ (2012) Damage to posterior parietal cortex impairs two forms of relational learning. Front Integr Neurosci 6:45. CrossRef Medline

Shibata H, Honda Y, Sasaki H, Naito J (2009) Organization of intrinsic connections of the retrosplenial cortex in the rat. Anat Sci Int 84:280-292. CrossRef Medline

Smith DM, Barredo J, Mizumori SJ (2012) Complimentary roles of the hippocampus and retrosplenial cortex in behavioral context discrimination. Hippocampus 22:1121-1133. CrossRef Medline

Sugar J, Witter MP, van Strien NM, Cappaert NL (2011) The retrosplenial cortex: intrinsic connectivity and connections with the (para)hippocampal region in the rat. An interactive connectome. Front Neuroinform 5:7. CrossRef Medline

Tulving E, Markowitsch HJ (1998) Episodic and declarative memory: role of the hippocampus. Hippocampus 8:198-204. CrossRef Medline

Urban DJ, Roth BL (2014) DREADDs (Designer Receptors Exclusively Activated by Designer Drugs): chemogenetic tools with therapeutic utility. Annu Rev Pharmacol, in press.

Vann SD, Aggleton JP (2002) Extensive cytotoxic lesions of the rat retrosplenial cortex reveal consistent deficits on tasks that tax allocentric spatial memory. Behav Neurosci 116:85-94. CrossRef Medline

Vann SD, Aggleton JP, Maguire EA (2009) What does the retrosplenial cortex do? Nat Rev Neurosci 10:792-802. CrossRef Medline

Wimmer GE, Shohamy D (2012) Preference by association: how memory mechanisms in the hippocampus bias decisions. Science 338:270-273. CrossRef Medline 